\title{
Correlative Study of Microstructure and Performance for Porous Transport Layers in Polymer Electrolyte Membrane Water Electrolysers by X-ray Computed Tomography and Electrochemical Characterization
}

\author{
Jude O. Majasan ${ }^{\mathrm{a}}$, Francesco Iacoviello ${ }^{\mathrm{a}}$, Jason I.S. Cho ${ }^{\mathrm{a}}$, Maximilian Maier ${ }^{\mathrm{a}}$, Xuekun Lu \\ Tobias P. Neville ${ }^{a}$, Ishanka Dedigama ${ }^{a}$, Paul R. Shearing ${ }^{a}$ and Daniel J. L. Brett ${ }^{a}{ }^{*}$ \\ ${ }^{a}$ Electrochemical Innovation Lab, Department of Chemical Engineering, University College London, \\ London, WC1E 7JE, UK \\ * Corresponding author: d.brett@ucl.ac.uk
}

\begin{abstract}
The porous transport layer (PTL) in polymer electrolyte membrane water electrolysers (PEMWEs) has the multiple roles of delivering water to the electro-catalyst, removal of product gas, and acts as a conduit for electronic and thermal transport. They are, thus, a critical component for optimized performance, especially at high current density operation. This study examines the relationship between the microstructure and corresponding electrochemical performance of commonly used titanium sinter PTLs. Four PTLs, with mean pore diameter (MPD) ranging from $16 \mu \mathrm{m}$ to $90 \mu \mathrm{m}$, were characterized ex-situ using scanning electron microscopy and X-ray computed micro-tomography to determine key structural properties. The performance of these PTLs was studied operando using polarization and electrochemical impedance spectroscopy. Results showed that an increase in mean pore size of the PTLs correlates to an increase in the spread and multimodality of the pore size distribution and a reduction in homogeneity of porosity distribution. Electrochemical measurements reveal a strong correlation of mean pore size of the PTLs with performance. Smaller pore PTLs showed lower Ohmic resistance but higher mass transport resistance at high current density of $3.0 \mathrm{~A} \mathrm{~cm}^{-2}$. A non-monotonic trend of mass transport resistance was observed for different PTLs, which suggests an optimal pore size beyond which the advantageous influence of macroporosity for mass transport is diminished. The results indicate that maximizing contact points between the PTL and the catalyst layer is the overriding factor in determining the overall performance. These results guide PTL design and fabrication of PEMWEs.
\end{abstract}

\section{Keywords:}


Polymer electrolyte membrane water electrolyser; pore size; two-phase flow; porous transport layer; electrochemical impedance spectroscopy; X-ray computed microtomography.

\section{Introduction}

Polymer electrolyte membrane water electrolysers (PEMWEs) are considered a highly promising technology for 'green' energy generation from renewable but intermittent energy sources such as solar and wind. PEMWEs possess several key advantages over conventional alkaline electrolysers, including high operational current density, high conversion efficiency, high purity of produced gases, rapid response, compact structure and high reliability [1-7]. Moreover, PEMWEs are robust and amenable to coupling with PEM fuel cells to create highly efficient regenerative energy storage systems. However, further performance and efficiency improvements, as well as simultaneous cost reduction are required for widespread integration and large-scale commercial deployment [3,8-14]. In order to satisfy the requirements of coupling with intermittent, highly dynamic, renewable energy generators (e.g., wind farms), operation at high current density is necessary [9]. However, a consequence of high current density operation is increased mass transport hindrance due to the need to deliver water to the electrode and removal of product gas. Thus, it is important to optimize cell components associated with water, gas and electron transport to minimize mass transport losses while maintaining good electrical contact.

The configuration of the PEM water electrolyser is similar to that of a PEM fuel cell as it consists of a membrane electrode assembly (MEA), porous transport layers (PTLs), bipolar plates with flow channels, and end-plates for cell/stack compression. Fig. 1 shows a schematic diagram of a typical PEMWE. The PTL, positioned between the MEA and bipolar plates at both electrode sides, is an important component of the PEMWE that facilitates the transport of liquid and gas between the electrodes and flow channels, as well as electrical and heat conduction within the cell. These functions of the PTL require high liquid permeability and gas diffusivity of the pore phase, and high electrical and thermal conductivity of the solid phase.

Ideally, the PTL contributes minimally to Ohmic, interfacial, thermal and mass transport losses, such that the liquid water is fed to the electrode and the product gas is expelled from the catalytic layer through the PTL unhindered. However, the build-up of oxygen gas in the form of bubbles (gas voids) in the vicinity of the anode can reduce the available active area for reaction, and gas bubbles trapped in the pores of the PTL could hinder mass transport of liquid water to the electrode. Therefore, the PTL plays a key role in determining the overall performance of PEMWEs. 
A PTL can be characterized by its morphology and structural parameters, such as powder size, porosity, pore size distribution, tortuosity, permeability, and thickness. It is, therefore, necessary to understand the effect of the structural properties and achieve a tailored pore morphology that optimizes electron, heat and mass transport across the porous structure. The anodic overpotential in the PEM electrolyser is much larger than the cathodic overpotential. Also, two-phase flow of water/gas at the anode, where water must be delivered for reaction, is more complex. Thus, research has primarily focused on the material and design of the anode PTL $[15,16]$.

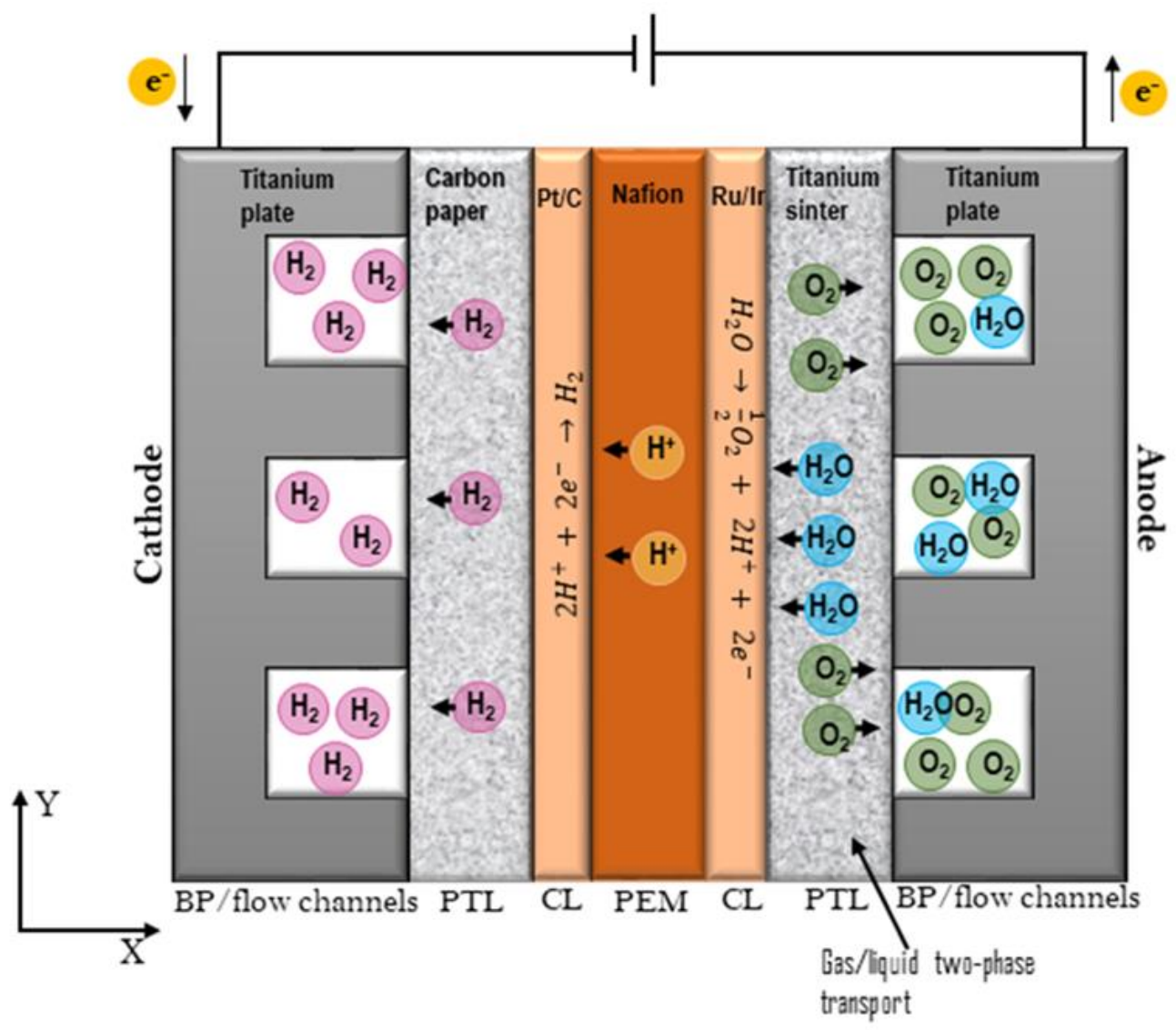

Fig. 1. Schematic of the PEMWE showing the two-phase water/gas counter-current flow in the anode PTL where liquid water is transported to the anode catalyst layer and product oxygen gas is expelled in the opposite direction.

Carbon fibre-based materials (carbon paper and cloth) typically used for PTLs in PEM fuel cells are unsuitable for use in PEM electrolyser anodes due to high operating potential, which corrodes carbon materials. Therefore, the commonly used anode PTLs in PEMWEs are titanium (Ti)-based materials such as sintered titanium powders, expanded sheets, felt type titanium fibre and titanium foam [16-21]. Several studies have reported that the 
performance of PEMWEs is influenced by structural parameters of the anode PTL, such as powder size, thickness, porosity and pore size [16-19,21-28].

Grigoriev et al. [17] were the first to experimentally investigate sintered powder PTLs in PEM electrolysers, and they suggested an optimal mean pore diameter (MPD) of 12-13 $\mu \mathrm{m}$, optimal porosity in the $30-50 \%$ range and optimal powder size in the range $50-75 \mu \mathrm{m}$ for $\mathrm{Ti}$ sintered powder PTLs. These values were proposed as a compromise between capillary effects, which manifest at pore sizes below $10 \mu \mathrm{m}$, and parasitic Ohmic losses associated with large pore sizes. Hwang et al. [18] investigated the effect of fibre size, MPD and porosity on performance using titanium felt PTLs in a unitized reversible fuel cell operating in electrolysis mode. They reported poorer performance with increase in MPD and fibre size, and suggested that the MPD, rather than porosity, is the more crucial parameter for electrolysis performance. Similar results for felt-type PTLs were reported by Ito et al. [19], where the electrolyser performance was found to deteriorate with increasing MPD when the MPD is larger than $10 \mu \mathrm{m}$. They pointed out that for porosity greater than $50 \%$, further increase in porosity had no significant effect on performance. In another study, Ito et al. [16], suggested that the oxygen bubbles produced at the anode may block the PTL when the MPD is less than $50 \mu \mathrm{m}$.

Microporous layers (MPLs) have been introduced for performance improvement in some studies, analogous to those used in PEMFCs [29-32]. Hwang et al. [25] investigated the integration of a backing or microporous layer by loading a $\mathrm{Ti}$ felt with $\mathrm{Ti}$ powder. Lettenmeier et al. [33] reported performance improvement at high current densities with MPL integration. The effect of transport properties such as thermal conductivity, electrical conductivity and permeability on cell performance have been investigated recently by Zielke et al. [34] using micro-computed tomography. The authors reported an exponential relationship between the PTL porosity and thermal conductivity, as well as between the inplane electrical conductivity and water permeability. More recently, Mo et al. [35-38] investigated PTLs with controlled morphologies using thin/tunable PTLs having a planar surface with straight-through pores, and reported promising results compared to the current state-of-the-art PTL designs.

From this review, the importance of the anode PTL design is highlighted by a clear relationship between the PTL microstructural properties and PEMWE performance. However, the structure-performance relationship is not yet fully understood, especially how the microstructural properties influences Ohmic and mass transport losses in the PEMWE at high current densities. In this work, four commercial sintered titanium powder PTLs with distinctive mean pore sizes are characterized ex-situ using scanning electron microscopy and $\mathrm{X}$-ray computed micro-tomography for properties such as surface morphology, pore size distribution, porosity, tortuosity, and porosity distribution. The microstructural properties 
are then correlated with electrochemical performance based on in-situ polarization curves and electrochemical impedance spectroscopy at current densities up to $3.0 \mathrm{~A} \mathrm{~cm}^{-2}$.

\section{Experimental}

\subsection{PTL Samples and PEMWE cell}

Four commercially available sintered titanium powder PTLs, coated with a layer of $0.5 \mu \mathrm{m}$ platinum for corrosion resistance, were purchased from Baoji Qixin Titanium Co, Ltd and used for this study. The technical data supplied by the manufacturer is summarized in Table 1. The samples are labelled as PD16, PD40, PD60 and PD90 where "PD" refers to "pore diameter" and the two-digit number that follows is the manufacturer-supplied values of the mean pore diameter. The mean pore diameter of the PTL is a key microstructural characteristic expected to influence performance [16-19,25]. According to the data, the PD90 sample has a mean pore diameter roughly six times that of PD16; this provides a wide range of pore diameter to investigate how PTL structure can affect electrolyser performance. As shown in Table 1, the PTLs have similar thicknesses of ca.1 $\mathrm{mm}$ and the powder size is in the range of $150-1000 \mu \mathrm{m}$.

The single PEMWE cell used in this study has an electrode area of $9 \mathrm{~cm}^{2}(3 \times 3 \mathrm{~cm})$ and has been detailed in a previous paper [39]. The flow-field plate for the anode and cathode sides were fabricated from $3 \mathrm{~mm}$-thick commercial grade titanium. The cathode-side flow plate consist of a single-serpentine flow channel $(1.76 \mathrm{~mm}$ width, $3 \mathrm{~mm}$ depth, and $1.76 \mathrm{~mm}$ land width), while the anode-side flow field consist of nine parallel channels $(1.76 \mathrm{~mm}$ width, $3 \mathrm{~mm}$ depth, and $1.76 \mathrm{~mm}$ land width). The MEA is the same as that used in our previous study [39], consisting of $3 \mathrm{mg} \mathrm{cm}^{-2}$ iridium/ruthenium oxide on the anode and $0.6 \mathrm{mg} \mathrm{cm}^{-2}$ platinum black on the cathode plated either side of a Nafion 115 membrane. Untreated Toray carbon-paper (Toray 090) was used as the PTL on the cathode side.

\begin{tabular}{lccc}
\hline PTL sample & $\begin{array}{c}\text { Mean pore } \\
\text { diameter }(\boldsymbol{\mu m})\end{array}$ & $\begin{array}{c}\text { Thickness } \\
(\mathbf{m m})\end{array}$ & $\begin{array}{c}\text { Particle size } \\
(\boldsymbol{\mu m})\end{array}$ \\
\hline PD16 & 16 & 1.00 & $150-250$ \\
PD40 & 40 & 1.00 & $270-380$ \\
PD60 & 60 & 1.09 & $380-830$ \\
PD90 & 90 & 1.04 & $380-1000$ \\
\hline
\end{tabular}

Table 1. Properties of the PTLs investigated in this study.

\subsection{Cell Setup}


The setup of the experimental test rig is shown in Fig. 2. DI water was supplied from a water tank to the PEMWE cell using a peristaltic pump (Watson Marlow 323U). Notionally, water needs only be supplied to the anode where it is split into molecular oxygen and protons and electrons. However, in this study, water was circulated to both electrodes to ensure the membrane remains well hydrated. All measurements were carried out at ambient pressure and the cell was heated to the desired temperature by preheating the circulating water supplied to both electrodes using a circulated heated bath (TC120, Grant Instruments Ltd.). The temperature of the inlet water was set at $80^{\circ} \mathrm{C}$. The excess unreacted DI water is separated from the product gases in the water reservoir/separating chamber and recycled to the cell, while the gases were vented.



Fig. 2. Schematic of experimental setup for electrolyser operation.

\subsection{Ex-situ Morphology and Microstructural Characterization}

\subsubsection{SEM Analysis}


The morphology of the surface of the PTLs, normally in contact with the catalyst layer, was observed using scanning electron microscopy (SEM, Zeiss EVO MA10, Carl Zeiss, USA). A $5 \mathrm{~mm}$ diameter disc of each PTL sample was cut and used for the imaging. The morphological investigation was performed in a secondary electron imaging mode at an electron accelerating voltage of $10 \mathrm{kV}$ and a working distance range of 8-8.5 mm. Images of the surface structure of the samples were captured and collected using the built-in SmartSEM ${ }^{\circledR}$ image acquisition and processing software.

\subsubsection{X-ray Computed Tomography Image Acquisition}

X-ray computed micro-tomography is a powerful non-invasive, non-destructive, radiographic $3 \mathrm{D}$ imaging technique which allows for both quantitative and qualitative investigation of the structure and properties of various materials [22,40-42]. It involves directing an X-ray beam towards the sample, while rotating the sample on a rotation stage about an axis perpendicular to the incident $\mathrm{X}$-ray beam. The $\mathrm{X}$-rays pass through the sample to create $2 \mathrm{D}$ slice images which reflects the local density and compositional variation within the sample. The series of $2 \mathrm{D}$ radiographs are then reconstructed into a $3 \mathrm{D}$ volume using mathematical transformation algorithms [43], from which tomograms, comprising of 3D elements called voxels (extension of the term pixel in $2 \mathrm{D}$ imaging), are extracted. This $3 \mathrm{D}$ data are then analysed using dedicated software packages to obtain 3D quantitative information about the sample structure.

In this study, X-ray tomographic image acquisition of the PTL microstructure was performed using X-ray computed micro-tomography (ZEISS Xradia Versa 520, Carl Zeiss X-ray Microscopy Inc., Pleasanton, CA). All samples were scanned in pristine state and the scans were carried out with a source voltage of $150 \mathrm{kV}$ with exposure time of $4 \mathrm{~s}$ per projection, acquiring 1801 projections per scan. The raw transmission images from the scan were reconstructed using a commercial image reconstruction package (Zeiss XMReconstructor, Carl Zeiss X-ray Microscopy Inc. Pleasanton, CA), which uses a conebeam filtered back-projection algorithm, resulting in a voxel volume of approximately 1.01 $\mu \mathrm{m}$. A sub-volume of $800^{3}$ voxels was extracted from each $3 \mathrm{D}$ volume to minimize computational requirements. An edge-preserving non-local means filter was applied to each dataset to reduce noise and aid phase segmentation. Segmentation of the solid and pore phases and 3D volume rendering of the resulting reconstructed volumes was performed using the Avizo software package (version 9.2. Thermo Fisher Scientific). Thresholding of the $3 \mathrm{D}$ volume was conducted based on the distinctive image contrast between the solid and pore phases, largely due to the disparate X-ray attenuation coefficients of titanium and air. Grey-scale and binary ortho-slices of each sample and 3D TIFF image files were generated. The segmented 3D TIFF image files were then processed for image-based quantification. The pore size distribution was obtained using commercial software (ImageJ v1.52d). The 
porosity distribution was obtained using pore quantification code implemented in MATLAB [44]. The bulk porosity and tortuosity factor were obtained using TauFactor, an open-source MATLAB software package which implements a diffusive flux-based approach for the determination of tortuosity factor [45].

\subsection{Electrochemical Characterizations}

Electrochemical characterization was performed using a Gamry Reference 3000 galvanostat/potentiostat equipped with a Gamry 30k Booster (Gamry Instruments, USA) and controlled by the Gamry Framework software (version 6.24).

In the steady state current-voltage polarization curves ( $i-V$ curves), the current density was increased from $0 \mathrm{~A} \mathrm{~cm}^{-2}$ to $3.0 \mathrm{~A} \mathrm{~cm}^{-2}$ in $0.1 \mathrm{~A}$ increments. An initial load of $1.0 \mathrm{~A} \mathrm{~cm}^{-2}$ was applied to the cell for 15 minutes before polarization curve measurements to ensure steadystate operation. In addition to randomising the order of the experiments, the polarization curves were generated in triplicates for each PTL and were highly reproducible (standard deviation $<3 \%$ ). The reported results are the average of the polarization curves generated.

Electrochemical impedance spectroscopy (EIS) was performed at current densities of 0.1 , 0.5 and $3.0 \mathrm{~A} \mathrm{~cm}^{-2}$ between $100 \mathrm{kHz}$ and $0.1 \mathrm{~Hz}$, with each test preceded by a conditioning period of 15 minutes at the respective current density to ensure steady-state operation. A variable AC perturbation of $5 \%$ of the DC value was applied which was confirmed to be small enough not to interfere with the cell performance. The anode served as the working electrode, whereas the cathode was used as both counter and reference electrode. Impedance measurements were also done in triplicates for each test condition and were highly reproducible (standard deviation $<0.5 \%$ ). The impedance data have been displayed in complex plane/Nyquist plots and the experimental impedance data were fitted using Zview software (Scribner Associates, Inc., v3.3d) to provide quantitative support for the discussion of the impedance results.

\section{Results and Discussion}

\subsection{Surface Morphology of PTL Samples by Scanning Electron Microscopy}

The morphology of the PTL surfaces was characterized using SEM. Fig. 3 presents the topview micrographs of the PTLs at 200× magnification. The SEM micrographs demonstrate significant differences in pore sizes across the four PTL samples consistent with the intended pore size variability for the study. PD16 and PD40 show a relatively micro-pore structure, whereas PD60 and PD90 show an open large macro-pore structure. The shape and size of the pores in the PTL samples was irregular, attributed to the nature of the sintering process, 
which involves agglomeration of titanium powder. In addition, several closed micropores can be observed on the surface of the PTLs, particularly of the larger pore PTLs. In a typical PEMWE configuration (see Fig. 1), the PTL is pressed directly against the electrode catalyst layer, and as the average pore size of the catalyst layer is about 10-200 $\mathrm{nm}[46,47]$ (one to two orders of magnitudes smaller than the average pore size of the PTL), it is estimated that the highly open macro-pore structure of the larger pore PTL samples, for instance PD60 and PD90 samples, would lead to a decrease in the number of PTL/catalyst layer connection per unit MEA area, and thus result in an increased interfacial contact resistance between the $\mathrm{PTL} /$ catalyst layer and the PTL/flow-field plate. This claim is verified later in this work.
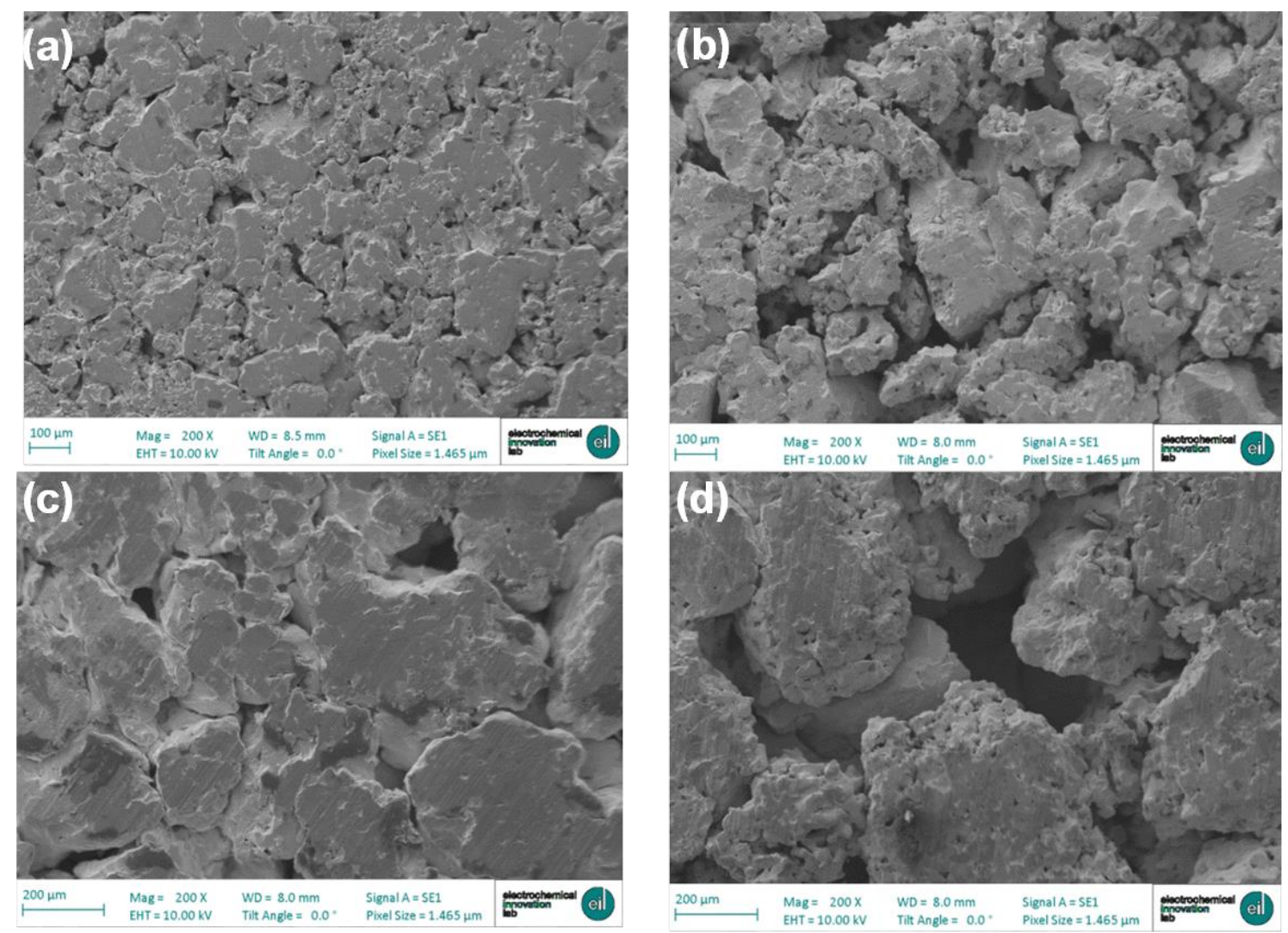

Fig 3. Bird's-eye view micrographs of the PTLs (200× magnification). (a) PD16 sample, (b) PD40 sample, (c) PD60 sample, and (d) PD90 sample.

\subsection{D Reconstruction, Pore Size Distribution, Porosity Distribution and Tortuosity Analysis}

The differences between samples in pore size and microstructure were further detected by Xray computed tomography and the segmented images are presented in Fig. 4. The binary images of the reconstructed tomograms show the highly X-ray-attenuating solid titanium in white and the less-attenuating pore spaces in black. The variation in pore sizes is visually 
distinguished with PD90 comprising bigger pores and wider pore size variation than the other samples. The PD16 sample shows a larger cross-sectional pore count, albeit with comparatively smaller-sized pores, while on the other hand, as the mean pore size increases, the cross-sectional number of pores and solid cluster decreased significantly.

The three-dimensional volume renderings of the PTL samples are shown in Fig. 5. The reconstructed 3D tomograms further reveal the variation in porous structure of the PTLs. A well-connected network of pores is apparent that offers a variety of continuous pathways through the solid structure. To further visualize the complementary pore spaces, the middle images (in green) show the connected pore network and also indicate the presence of isolated pores in the structures. Isolated pores are generally unavailable to fluid transport and might influence the performance of the PTLs.

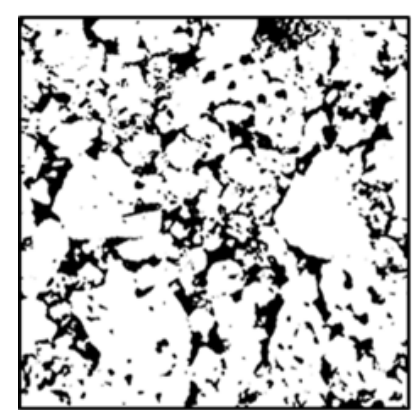

(a) PD16

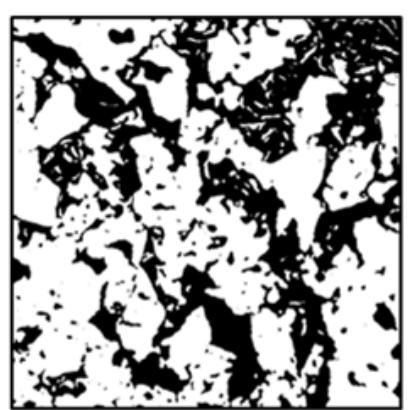

(b) PD40

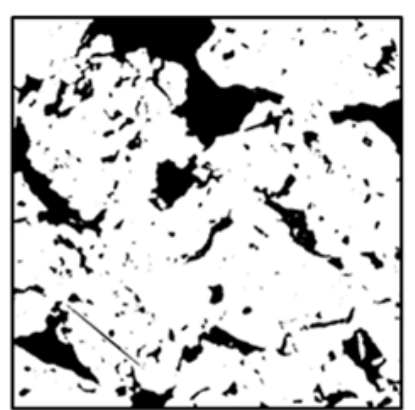

(c) PD60

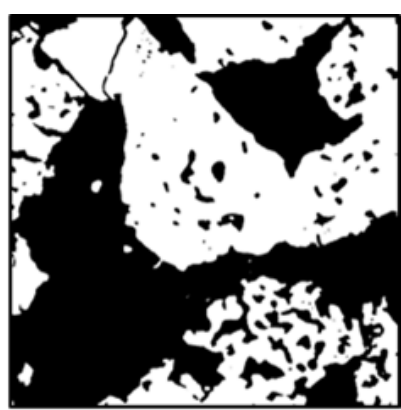

(a) $\mathrm{PD} 90$

Fig. 4. Binarized tomography ortho slices corresponding to (a) PD16, (b) PD40, (c) PD60, and (d) PD90. The pores are shown in black and the solid phase in white. 


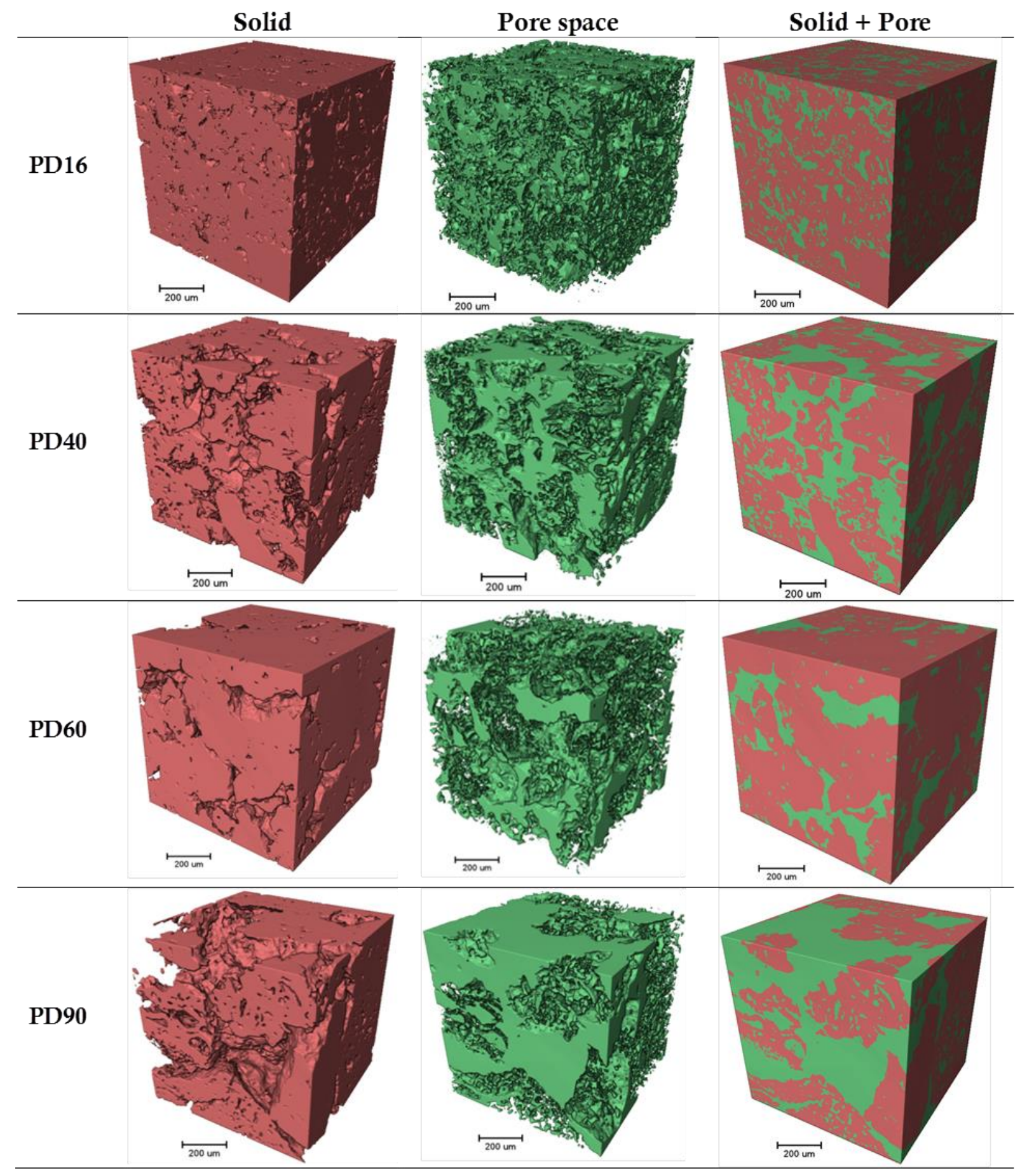

Fig. 5. 3D volume renderings of the PTL samples; (a) PD16 (b) PD40 (c) PD60 and (d) PD90. Each cube is an extracted $800^{3}$ volume with the solid phase in red and pore space in green.

The pore size distribution and the corresponding cumulative frequencies (on the basis of pore volume) for the PTL samples are shown in Fig. 6. The distribution broadens with 
increasing powder size/MPD, with the PD90 sample exhibiting a range of pore sizes an order of magnitude larger than that of the PD16. Although pore sizes as small as $1 \mu \mathrm{m}$ were observed in all the samples, the maximum pore diameter was $46 \mu \mathrm{m}$ for PD16 compared to $263 \mu \mathrm{m}$ for PD90. Also, a greater variability in pore distribution of the larger MPD samples was apparent. For example, PD16 shows a narrow band of pore sizes, where pores with diameter $\leq 18 \mu \mathrm{m}$ constitute about $80 \%$ of pores; whereas broader bands of pore sizes are seen for larger MPDs. PD90, for instance, shows an apparent multimodality where at least two distinct pore clusters can be observed with $40 \%$ of pores having a diameter $\leq 50 \mu \mathrm{m}$, and another peak between 70 and $110 \mu \mathrm{m}$ representing another $40 \%$ of the total pore volume. It is suggested that PTLs with a larger pore size/pore volume could enhance mass transport, but at a cost of decreased electrical conductivity. Detailed quantification of pore size and pore volume fraction is summarized in Table 2 .
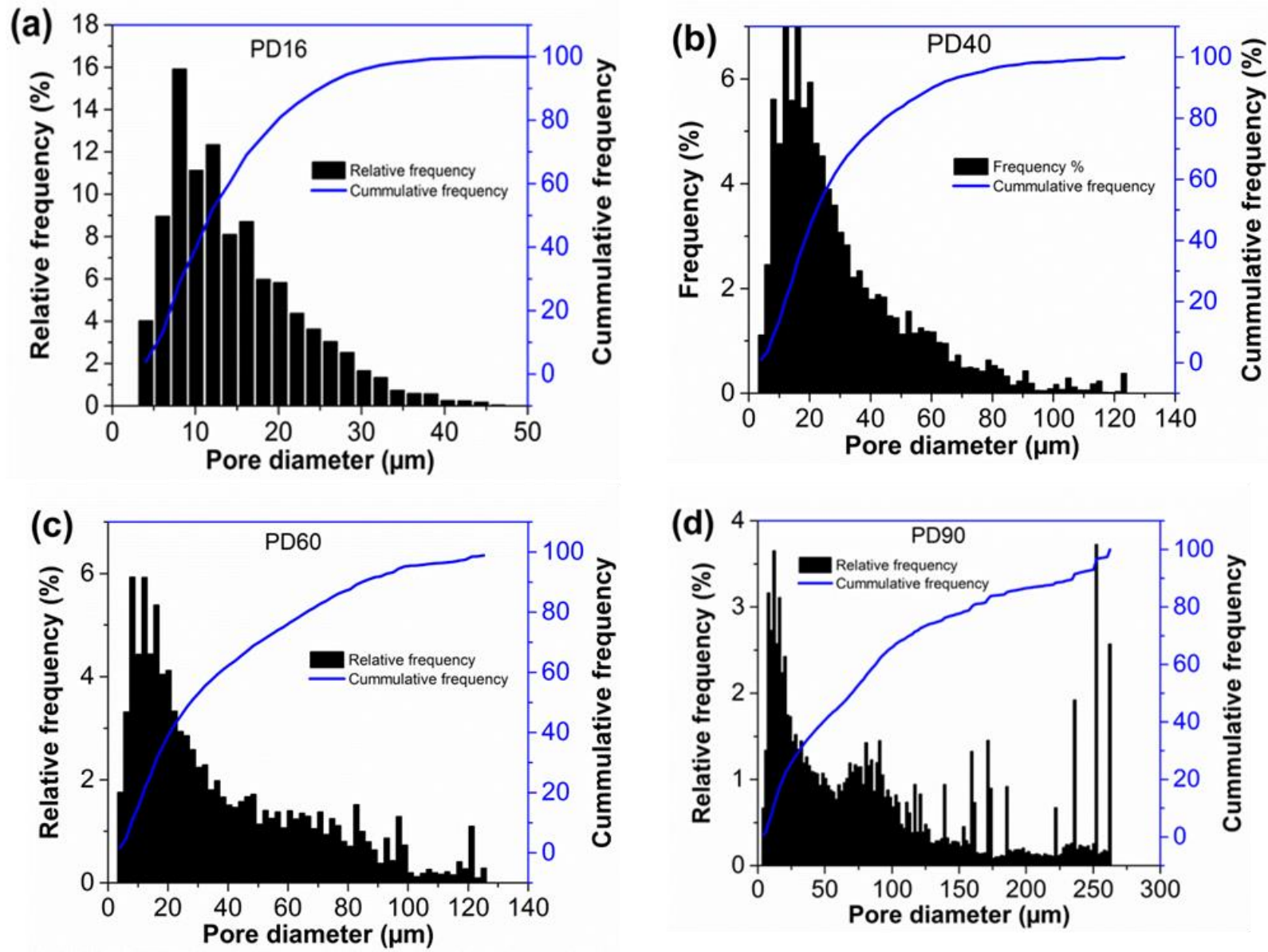

Fig 6. Pore size distribution in (a) PD16, (b) PD40, (c) PD60, and (d) PD90. 


\begin{tabular}{lcccc}
\hline & PD16 & PD40 & PD60 & PD90 \\
\hline Pore volume fraction & 21.84 & 35.56 & 20.39 & 37.83 \\
Mean Pore diameter $(\boldsymbol{\mu m})$ & 14.66 & 30.28 & 38.00 & 90.96 \\
Maximum pore diameter $(\boldsymbol{\mu m})$ & 45.51 & 123.16 & 125.18 & 262.47 \\
\hline
\end{tabular}

Table 2. Quantitative analysis of pore size distribution of PTLs from X-ray computed tomography.

To evaluate the homogeneity of the pores along the PTL thickness, the slice-wise porosity distribution was extracted from the reconstructed 3D volume. Each slice was $\sim 1.01 \mu \mathrm{m}$ for all the PTL samples limited by the spatial/slice resolution. The areal porosity in the $x-y$ plane along the PTL thickness were analysed and presented in Fig. 7(a). Fluctuations in porosity along the PTL thickness is observed, due to the apparent random structure of the PTLs. As can be seen from Fig 7(b), higher standard deviation values are obtained at larger mean pore diameter of the PTLs, which indicates higher heterogeneity in the PTL porous structure with increase in mean pore size. Fig. 7(b) also shows the average fraction of the porosity distribution. The average areal porosity fraction of PTLs was $21.84 \%, 35.56 \%$, $20.39 \%$ and $37.83 \%$ respectively. In general, the average areal porosity was higher for larger pore PTLs. However, PD60 shows an unexpectedly low average areal porosity attributed to the powder packing during manufacturing, which might suggest that the porosity does not scale directly with powder size but is also influenced by the powder packing during the manufacturing process. 

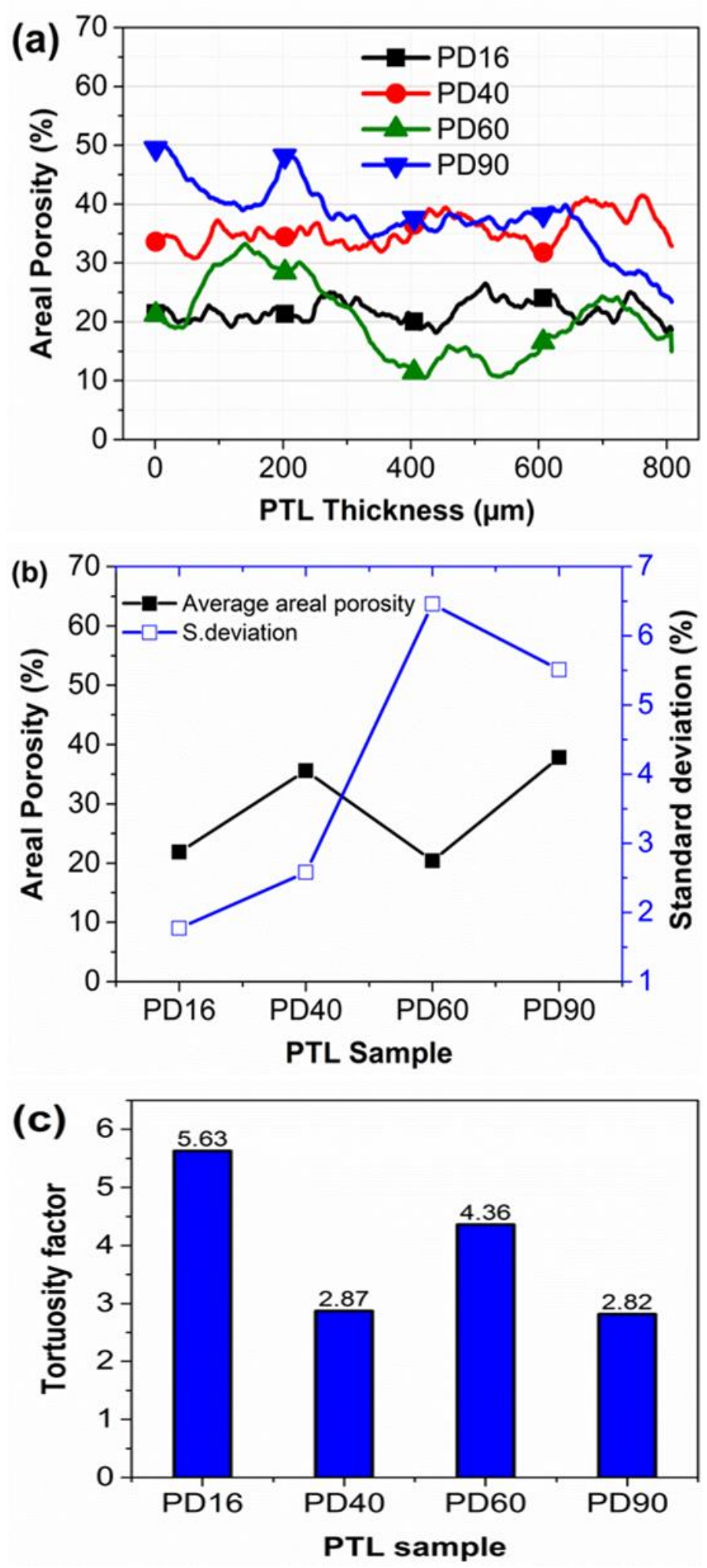

Fig. 7 (a) Areal porosity distribution showing slice-by-slice porosity in the through-plane (thickness) direction for the PTL samples, (b) average value and standard deviation of porosity, and (c) tortuosity factor for the PTLs in the $z$-direction (along the PTL thickness). 
Fig. 7(c) presents the tortuosity factor of the PTLs in the through-plane direction. The tortuosity factor is a measure of the resistance to diffusive transport caused by convolutions in the flow paths [48]. The values obtained for the tortuosity factors are 5.63, 2.87, 4.36 and 2.82 for PD16, PD40, PD60 and PD90, respectively. This suggest PD16 has the most tortuous flow path of the PTLs with the PD90 being the least tortuous. The tortuosity was unexpectedly higher in PD60; however, this is consistent with the observations presented in Fig. 6 and Fig. 7(a) and (b), which show the less porous structure of this particular sample. The samples with higher porosity (PD40 and PD90) also show a lower tortuosity factor while the low porosity samples (PD16 and PD60) show a higher tortuosity. This is the first time this relationship has been observed for titanium sinter used for PEMWEs; however, this inverse relationship between porosity and tortuosity has been invoked when analyzing transport phenomena in electrochemical systems $[41,49]$. The quantification of tortuosity is relevant to performance due to the dependency of permeability and effective diffusivity and hence, mass transport on tortuosity. It is expected that increase in tortuosity of the PTL would be unfavourable for mass transport and contribute to mass transport resistance due to reduced effective gas/liquid diffusion.

\subsection{Polarization Behaviour of the PEMWE with Various PTLs}

In this section, the electrochemical performance of the various PTLs is investigated. The cell polarization performance of the four PTLs was studied at water feed rate of $15 \mathrm{ml} \mathrm{min}^{-1}$ (Fig. 8). The measurements were performed at ambient pressure and an inlet water temperature of $80^{\circ} \mathrm{C}$. All operating parameters and PEMWE components were kept the same between cell assemblies with only the PTL varied. As seen in Fig. 8(a), PD16 shows the best performance (lowest cell potential at a given current density) of the four PTLs at both water feed rates and the performance decreased monotonically in the order PD16 > PD40 > PD60 > PD90. For instance, at $15 \mathrm{ml} \mathrm{min}^{-1}$ and a current density of $3.0 \mathrm{~A} \mathrm{~cm}^{-2}$, the cell potential was $2.54 \mathrm{~V}$ for PD16, 2.64 V for PD40, 2.65 V for PD60 and 2.74 V for PD90. The cell performance was similar for all four PTLs at low current density. However, as current density increased, the influence of the PTLs became apparent. The difference in cell performance observed is attributed to the difference in the PTL microstructure since test conditions and components were maintained with only the PTL changed. Notably, the order of performance of the PEMWE with the various PTLs was consistent with the MPD of the PTLs. Considering this, the correlation of MPD and cell performance was tested. As shown in Fig. $8(\mathrm{~b})$, a strong linear correlation $\left(\mathrm{R}^{2} \approx 0.93\right)$ is evident. This apparent strong correlation of increase in MPD with deterioration of performance (increase in cell voltage) is consistent with previous findings by other researchers [17-19]. 
Although the polarization curve provides a good qualification of overall cell performance, it does not lend itself readily to quantification of the individual overpotential effects. In the next section, electrochemical impedance spectroscopy is used to deconvolute the various voltage contributions [50-53].
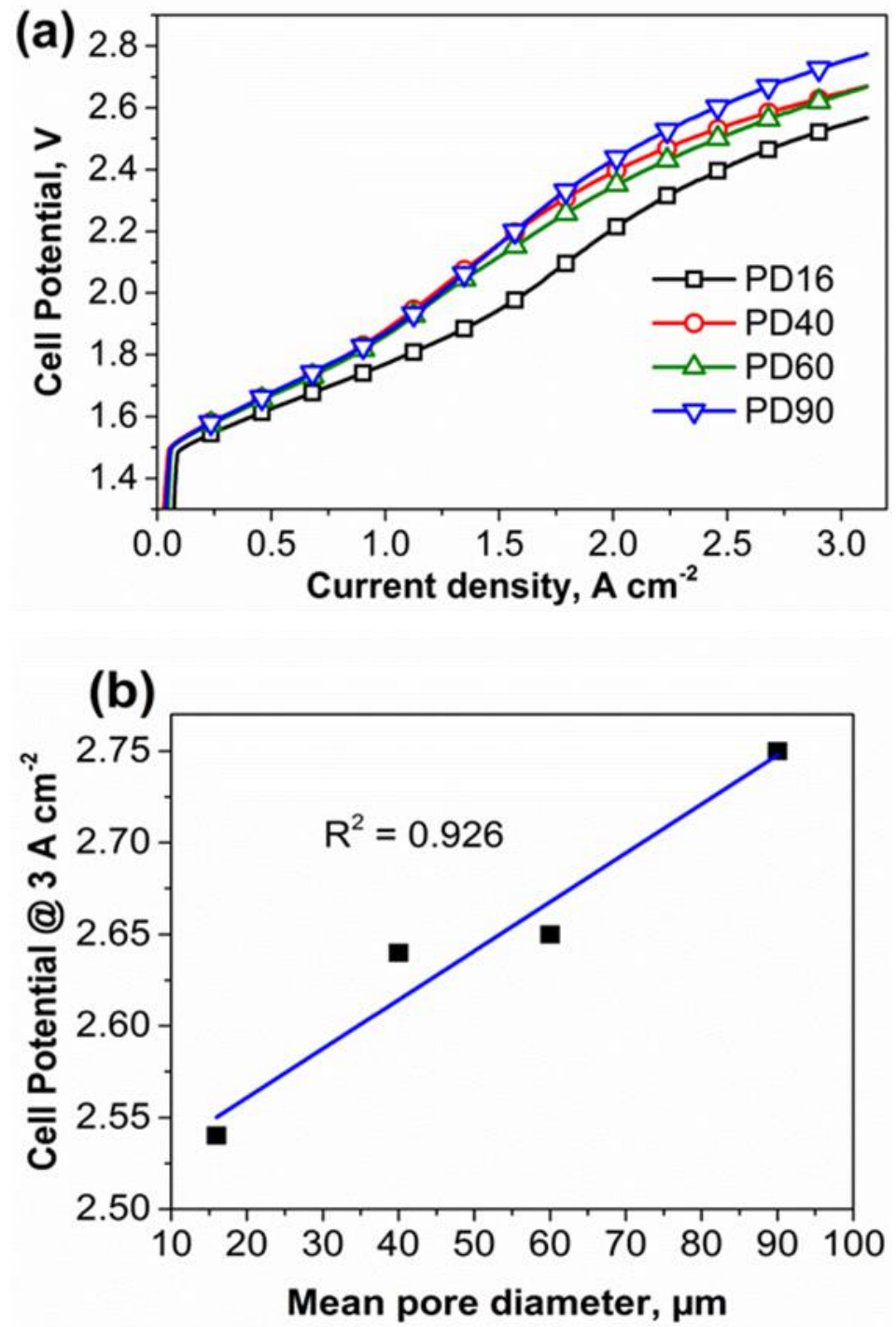

Fig. 8. (a) Polarization curves showing the performance of the four PTLs at water feed rate of $15 \mathrm{ml} \mathrm{min}{ }^{-1}$ and ambient pressure. (b) Correlation of mean pore diameter and cell potential at current density of $3.0 \mathrm{~A} \mathrm{~cm}^{-2}$.

\subsection{Electrochemical Impedance Spectroscopy of the PEMWE with Various PTLs}

Electrochemical impedance spectroscopy was applied at $0.1,0.5$ and $3.0 \mathrm{~A} \mathrm{~cm}^{-2}$ to enable evaluation of the overpotentials at 'low', 'medium' and 'high' current densities, respectively. 
Fig. 9 shows the impedance response of the PEMWE cell in a Nyquist plot representation measured at the various current densities. The measurements were performed at $80{ }^{\circ} \mathrm{C}$, at atmospheric pressure and volumetric water feed rate of $15 \mathrm{ml} \mathrm{min}{ }^{-1}$. The insets for current densities of 0.5 and $3.0 \mathrm{~A} \mathrm{~cm}^{-2}$, shows the high frequency intercept of the Nyquist plot normalized to zero for direct visual comparison of the impedance arcs.
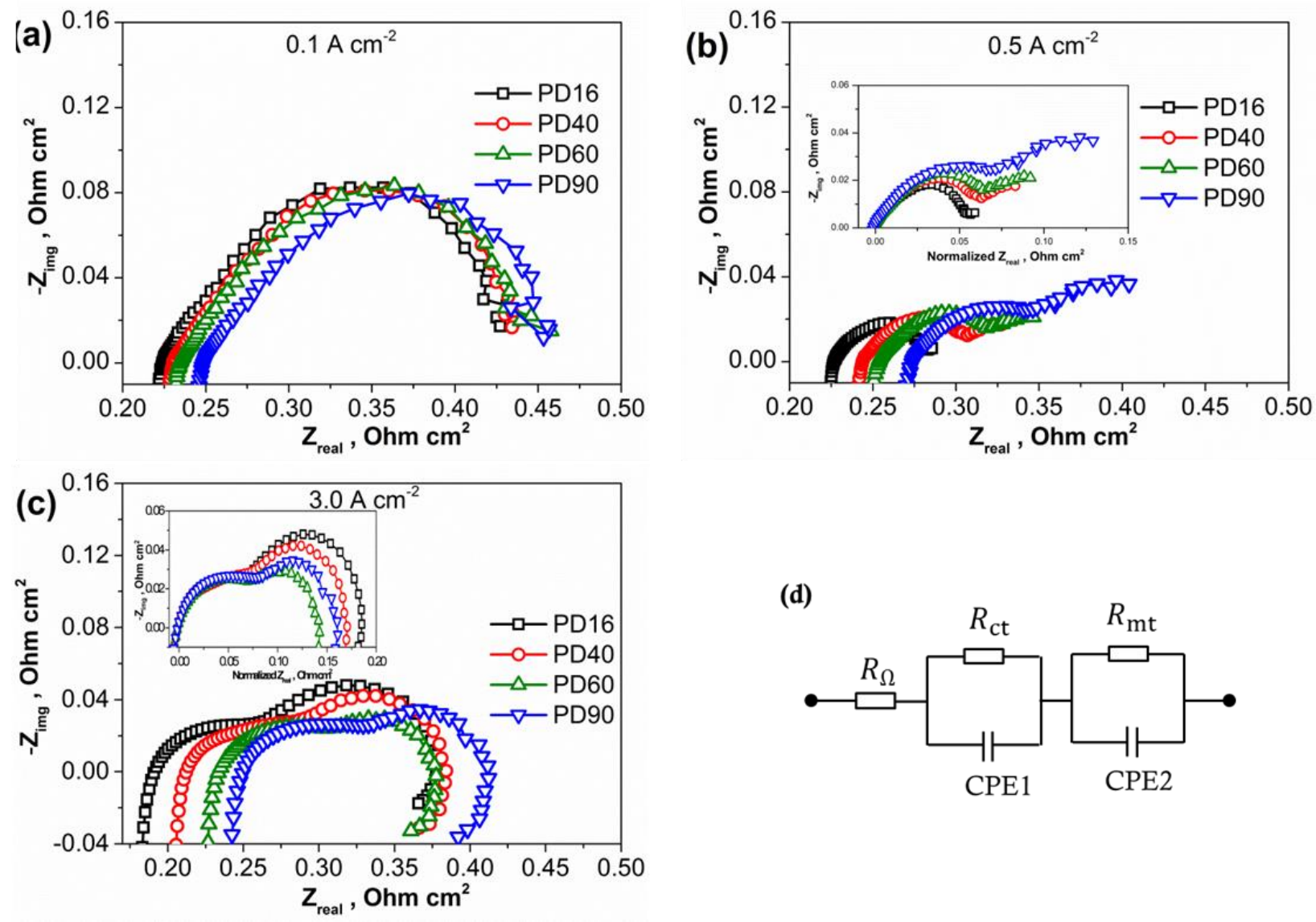

(d)

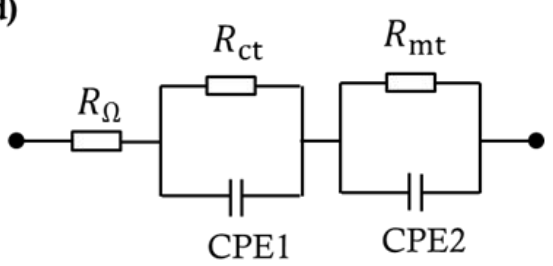

Fig. 9. Nyquist plots showing the performance of the various PTLs at a water feed rate of 15 $\mathrm{ml} \mathrm{min}{ }^{-1}$ and a current density of (a) $0.1 \mathrm{~A} \mathrm{~cm}^{-2}$ (b) $0.5 \mathrm{~A} \mathrm{~cm}^{-2}$ and (c) $3.0 \mathrm{~A} \mathrm{~cm}^{-2}$. The insets show the same graph on a normalized $x$-axis for visual comparison. (d) Equivalent circuit for the electrolyser cell showing the Ohmic, charge transfer resistances and mass transport resistances.

At current density of $0.1 \mathrm{~A} \mathrm{~cm}^{-2}$ (Fig. 9a), the Nyquist plot consist of two main features: a single capacitive arc, whose width corresponds to the charge transfer resistance and a highfrequency inductive response attributed to the parasitic inductance present in the system [53]. At this current density, the Nyquist plots show a similar diameter for the capacitive arc of each PTL, suggesting negligible impact of the variation of PTL properties on the charge transfer resistance. However, the Ohmic resistance, represented by the high frequency intercept with the real axis, varied and increased monotonically in the order PD16 < PD40 
$<$ PD60 < PD90; corresponding to the increase in the MPD and the trend in the polarization curve presented in Fig. 8(a). The Ohmic resistance comprises the bulk resistances of the membrane/PTL/bipolar plate resistance and their interfacial contact resistance. However, since the same PEMWE construction is used in all the cases, with the only change being the PTLs, the increase in Ohmic resistance can be ascribed to the increase in mean pore diameter of the samples leading to increased interfacial contact resistance between the PTL surface and the electrode layer. This is explained by the fact that the electrons must move longer distances, on average, along the surface of the catalyst layer before a contact between the catalyst layer and the PTL is found in the case of the larger pore PTL. Thus, the Ohmic resistance is lowest for PD16 and highest for PD90.

With increase in current density to $0.5 \mathrm{~A} \mathrm{~cm}^{-2}$ (Fig. 9b), in addition to the charge transfer capacitive arc at high frequency, a second inchoate arc is seen at low frequencies. This is attributed to mass transport limitations $[33,51,52,54]$ and increases with larger mean pore diameter. One explanation is the positive influence of capillary-driven water transport, which is greater for smaller pore diameters. Further increase in current density to $3.0 \mathrm{~A} \mathrm{~cm}^{-2}$ results in an increase in the low frequency arc as seen in the inset in Fig. 9(c). Here, the mass transfer arc for PD60 is the smallest and largest for PD16, indicating that at elevated current density, the mass transport resistance is highest in the PTL with the smallest average pore size. The size of the low frequency arc from the smallest to the largest was in the order PD60 < PD90 < PD40 < PD16. This shows a trend towards reduced mass transport limitation with increased pore size; however, the trend is non-monotonic, suggesting that there is an optimal pore size that minimises overall mass transfer limitations.

It is worth noting that a pseudo-inductive feature is observed at low frequency. Lowfrequency pseudo-inductive loops are known to be caused by adsorption processed reactions with intermediate species such as the poisoning of PEM fuel cell anodes by carbon monoxide and water transport characteristics in the membrane [55]. However, the reason for it here at high current density is unclear but may be associated with a change in the macroscopic two-phase flow regime, which is known to influence local current density $[52,56]$.

\subsection{Contributions of Individual Losses in the PEMWE Cell with Various PTLs}

In order to evaluate the relative effect of the losses in the PEMWE cell, the various resistances were quantified by equivalent resistance analysis. The impedance spectra were fit to the equivalent circuit shown in Fig 9(d). The intercept with the real axis represent the Ohmic resistance in the electrolyser cell and represented by a resistor $\left(R_{\Omega}\right)$. The high and low frequency arcs are attributed to the anode charge transfer and mass transport process in 
the PEMWE represented by $\left(R_{c t} C P E 1\right)$ and $\left(R_{m t} C P E 2\right)$ respectively. Constant phase elements (CPE) were used instead of pure capacitances to account for the porous nature of the electrode. The variation of the various resistances (Ohmic $R_{\Omega}$, charge transfer $R_{c t}$, and mass transport $R_{m t}$ resistances) for different current densities, obtained from the equivalent circuit model is presented in Fig. 10. It is noted that the Ohmic resistance increased approximately linearly with increase in MPD, across all three current densities (Fig 10a). At $3.0 \mathrm{~A} \mathrm{~cm}^{-2}$, the Ohmic resistance increased from $0.19 \Omega \mathrm{cm}^{2}$ in PD16 to $0.25 \Omega \mathrm{cm}^{2}$ in PD90 confirming the higher Ohmic resistance of the larger pore PTL. The charge transfer resistance, $R_{c t}$, decreased by about threefold from $0.22 \Omega \mathrm{cm}^{2}$ to $0.07 \Omega \mathrm{cm}^{2}$ as current density increased from $0.1 \mathrm{~A} \mathrm{~cm}^{-2}$ to $3.0 \mathrm{~A} \mathrm{~cm}^{-2}$ showing the faster activation and reaction kinetics at high current density. No major difference or clear trend in the charge transfer resistance with MPD (Fig. 10b) was observed, indicating the PTL has no significant effect on the electro-catalysis in the electrode. Mass transport resistance was observed at intermediate current density $\left(0.5 \mathrm{~A} \mathrm{~cm}^{-2}\right)$ and at elevated current density $\left(3.0 \mathrm{~A} \mathrm{~cm}^{-2}\right)$ but was higher, as expected, at high current density. Also, at the high current density (Fig. 10d), the mass transport resistance decreased with increasing MPD up to PD60 then increased at PD90 which suggests an optimal mean pore diameter beyond which mass transport resistance would increase. Overall, across the PTLs from PD16 to PD90, $R_{\Omega}$ increased by $\sim 0.06 \Omega \mathrm{cm}^{2}$ whereas $R_{m t}$ decreased by $\sim 0.04 \Omega \mathrm{cm}^{2}$ at $3.0 \mathrm{~A} \mathrm{~cm}{ }^{-2}$ and $R_{\mathrm{ct}}$ was relatively unchanged. Thus, a net increase in Ohmic resistance suggests that the Ohmic resistance is the overriding factor in determining cell performance over this current density range. 

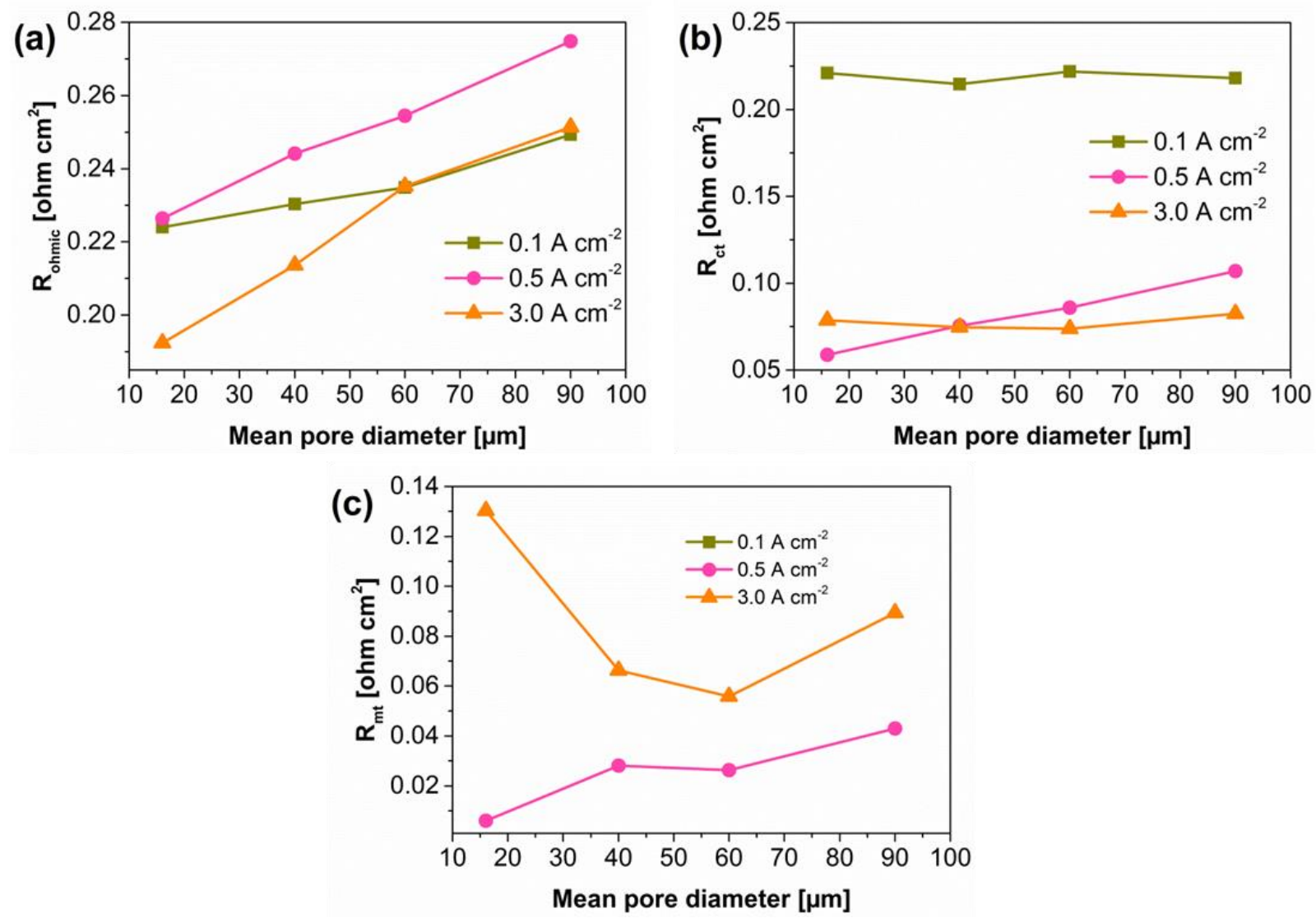

Fig.10. Comparison of EIS parameters using equivalent circuit models at current densities of $0.1,0.5$ and $3.0 \mathrm{~A} \mathrm{~cm}^{-2}$ (a) Ohmic resistance, $R_{\Omega}$ (b) charge transfer resistance, $\mathrm{R}_{\mathrm{ct}}$ and (c) mass transport resistance, $\mathrm{R}_{\mathrm{mt}}$.

The electrochemical analysis showed that there is a trade-off to consider for PTL design: smaller pore size results in better electron conductivity but poorer two-phase liquid-gas mass transport at high current density. Smaller pore PTLs result in lower interfacial contact resistance, as there are more contact points with the catalyst layer. However, the better Ohmic resistance is at the expense of mass transport capability at high current density.

The mass transport resistance trend in relation to pore size and current density implies that multiple factors are at play. Effective mass transport in a PTL involves water ingress and access to the catalyst as well as product gas $\left(\mathrm{O}_{2}\right)$ egress. At lower current density of $0.5 \mathrm{~A}$ $\mathrm{cm}^{-2}$ (Fig. 9(b)), where mass transport effects start to become noticeable, the mass transport resistance follows a trend where smaller pores lead to better mass transport, as would be promoted by capillary-driven water transport. However, at higher current density of $3 \mathrm{~A} \mathrm{~cm}^{-}$ ${ }^{2}$ (Fig. 9(c)), the rate of gas generation is significantly higher and mass transport can be expected to be limited by how rapidly $\mathrm{O}_{2}$ can be expelled from the system, the results implying that larger pores do this more effectively. The compound effect of these two factors leads to an optimum MPD of $\sim 60 \mu \mathrm{m}$. 
Overall, the apparent trade-off between minimized interfacial contact resistance (at small pore size) and maximized mass transport ability (at large pore size) must be carefully considered for optimized PTL design for PEMWEs, especially at high current density operations where mass transport becomes a limiting factor. Therefore, it is suggested that a graded pore size PTL would be most beneficial, in aggregating the advantage of the reduced interfacial resistance at smaller pore and improved mass transport at larger pores.

\section{Conclusions}

In this work, a correlative study of PTL microstructure and operando electrochemical performance was performed. The microstructural properties of the PTLs, such as surface morphology, pore size distribution, porosity, tortuosity, and porosity distribution were investigated ex-situ by scanning electron microscopy (SEM) and X-ray computed microtomography. The electrochemical performance of the PTLs was investigated by steady-state polarization and electrochemical impedance spectroscopy at various operating conditions. The main conclusions are summarized as follows:

(1) Increase in the mean pore diameter of the PTLs correlated with increase in multimodality of pore size distribution and heterogeneity of the porous structure.

(2) The polarization curve showed that cell performance decreased with increase in mean pore diameter from PD16 to PD90. Thus, PD16 showed the best overall polarization performance.

(3) Impedance study revealed a net increase in Ohmic resistance in the cell which suggests that the Ohmic resistance is a more significant net contributor to PTL performance in the PEMWE within the current density range studied. Thus, the Ohmic resistance might be more dominant over a wider polarization range than is expected.

(4) Smaller pore size of PTLs resulted in better electron conductivity but poorer mass transport at high current density. Improved mass transport was enabled by a larger pore size, although a non-monotonic trend suggests an optimal pore size beyond which the advantageous influence of macroporosity for mass transport is diminished.

(5) Overall, the result suggests that the effectiveness of the PTL can be significantly improved if the interfacial contact resistance can be minimized. Thus, it is suggested that graded pore size PTL would be most beneficial in aggregating the advantage of the reduced interfacial contact resistance at smaller pore and improved mass transport at larger pores.

\section{Acknowledgments}

JOM gratefully acknowledges the Presidential Scholarship for Innovation and Development, Nigeria for supporting his research. DB and PRS acknowledge 
the EPSRC for supporting hydrogen research in the Electrochemical Innovation Lab through

(EP/M014371/1, EP/M023508/1, EP/M009394/1, EP/L015749/1, EP/K038656/1 and $\mathrm{EP} / \mathrm{N} 022971 / 1)$.

\section{References}

[1] Barbir F. PEM electrolysis for production of hydrogen from renewable energy sources. Sol Energy 2005;78:661-9. doi:10.1016/j.solener.2004.09.003.

[2] Clarke RE, Giddey S, Ciacchi FT, Badwal SPS, Paul B, Andrews J. Direct coupling of an electrolyser to a solar PV system for generating hydrogen. Int J Hydrogen Energy 2009;34:2531-42. doi:10.1016/j.ijhydene.2009.01.053.

[3] Carmo M, Fritz DL, Mergel J, Stolten D. A comprehensive review on PEM water electrolysis. Int J Hydrogen Energy 2013;38:4901-34.

doi:10.1016/j.ijhydene.2013.01.151.

[4] Grigoriev SA, Porembsky VI, Fateev VN. Pure hydrogen production by PEM electrolysis for hydrogen energy. Int. J. Hydrogen Energy, vol. 31, 2006, p. 171-5. doi:10.1016/j.ijhydene.2005.04.038.

[5] Dunn S. Hydrogen futures: Toward a sustainable energy system. Int J Hydrogen Energy 2002;27:235-64. doi:10.1016/S0360-3199(01)00131-8.

[6] An L, Zhao TS, Chai ZH, Tan P, Zeng L. Mathematical modeling of an anionexchange membrane water electrolyzer for hydrogen production. Int J Hydrogen Energy 2014. doi:10.1016/j.ijhydene.2014.10.025.

[7] Maier M, Meyer Q, Majasan J, Tan C, Dedigama I, Robinson J, et al. Operando flow regime diagnosis using acoustic emission in a polymer electrolyte membrane water electrolyser. J Power Sources 2019. doi:10.1016/j.jpowsour.2019.03.061.

[8] Babic U, Suermann M, Büchi FN, Gubler L, Schmidt TJ. Critical ReviewIdentifying Critical Gaps for Polymer Electrolyte Water Electrolysis Development. J Electrochem Soc 2017;164:F387-99. doi:10.1149/2.1441704jes.

[9] Lettenmeier P, Wang R, Abouatallah R, Helmly S, Morawietz T, Hiesgen R, et al. Durable Membrane Electrode Assemblies for Proton Exchange Membrane Electrolyzer Systems Operating at High Current Densities. Electrochim Acta 2016;210:502-11. doi:10.1016/j.electacta.2016.04.164.

[10] Bertuccioli L, Chan A, Hart D, Lehner F, Madden B, Standen E. Study on development of water electrolysis in the EU, Fuel Cells and hydrogen Joint Undertaking. 2014.

[11] Millet P, Ranjbari A, de Guglielmo F, Grigoriev SA, Aupr?tre F. Cell failure mechanisms in PEM water electrolyzers. Int J Hydrogen Energy 2012;37:17478-87. doi:10.1016/j.ijhydene.2012.06.017.

[12] Marshall A, Børresen B, Hagen G, Tsypkin M, Tunold R. Electrochemical characterisation of IrxSn1-xO2powders as oxygen evolution electrocatalysts. Electrochim Acta 2006;51:3161-7. doi:10.1016/j.electacta.2005.09.004.

[13] Aubras F, Deseure J, Kadjo JJA, Dedigama I, Majasan J, Grondin-Perez B, et al. Two-dimensional model of low-pressure PEM electrolyser: Two-phase flow regime, electrochemical modelling and experimental validation. Int J Hydrogen Energy 2017. 
doi:10.1016/j.ijhydene.2017.08.211.

[14] Omrani R, Shabani B. Gas diffusion layer modifications and treatments for improving the performance of proton exchange membrane fuel cells and electrolysers: A review. Int J Hydrogen Energy 2017. doi:10.1016/j.ijhydene.2017.09.132.

[15] Millet P. PEM Water Electrolysis. Hydrog. Prod., Weinheim, Germany: Wiley-VCH Verlag GmbH \& Co. KGaA; 2015, p. 63-116. doi:10.1002/9783527676507.ch3.

[16] Ito H, Maeda T, Nakano A, Kato A, Yoshida T. Influence of pore structural properties of current collectors on the performance of proton exchange membrane electrolyzer. Electrochim Acta 2013;100:242-8. doi:10.1016/j.electacta.2012.05.068.

[17] Grigoriev SA, Millet P, Volobuev SA, Fateev VN. Optimization of porous current collectors for PEM water electrolysers. Int J Hydrogen Energy 2009;34:4968-73. doi:10.1016/j.ijhydene.2008.11.056.

[18] Hwang CM, Ishida M, Ito H, Maeda T, Nakano A, Hasegawa Y, et al. Influence of properties of gas diffusion layers on the performance of polymer electrolyte-based unitized reversible fuel cells. Int J Hydrogen Energy 2011;36:1740-53. doi:10.1016/j.ijhydene.2010.10.091.

[19] Ito H, Maeda T, Nakano A, Hwang CM, Ishida M, Kato A, et al. Experimental study on porous current collectors of PEM electrolyzers. Int J Hydrogen Energy 2012;37:7418-28. doi:10.1016/j.ijhydene.2012.01.095.

[20] Millet P, Andolfatto F, Durand R. Design and performance of a solid polymer electrolyte water electrolyzer. Int J Hydrogen Energy 1996;21:87-93. doi:10.1016/0360-3199(95)00005-4.

[21] Arbabi F, Kalantarian A, Abouatallah R, Wang R, Wallace JS, Bazylak A. Feasibility study of using microfluidic platforms for visualizing bubble flows in electrolyzer gas diffusion layers. J Power Sources 2014;258:142-9. doi:10.1016/j.jpowsour.2014.02.042.

[22] Suermann M, Takanohashi K, Lamibrac A, Schmidt TJ, Büchi FN. Influence of Operating Conditions and Material Properties on the Mass Transport Losses of Polymer Electrolyte Water Electrolysis. J Electrochem Soc 2017;164. doi: $10.1149 / 2.13517109$ jes.

[23] Lee CH, Hinebaugh J, Banerjee R, Chevalier S, Abouatallah R, Wang R, et al. Influence of limiting throat and flow regime on oxygen bubble saturation of polymer electrolyte membrane electrolyzer porous transport layers. Int J Hydrogen Energy 2017;42:2724-35. doi:10.1016/j.ijhydene.2016.09.114.

[24] Ito H, Maeda T, Nakano A, Hwang CM, Ishida M, Yokoi N, et al. Influence of different gas diffusion layers on the water management of polymer electrolyte unitized reversible fuel cell. ECS Trans., vol. 33, 2010. doi:10.1149/1.3484588.

[25] Hwang CM, Ishida M, Ito H, Maeda T, Nakano A, Kato A, et al. Effect of titanium powder loading in gas diffusion layer of a polymer electrolyte unitized reversible fuel cell. J Power Sources 2012;202:108-13. doi:10.1016/j.jpowsour.2011.11.041.

[26] Fritz DL, Mergel J, Stolten D. PEM Electrolysis Simulation and Validation. ECS Trans 2014;58:1-9. doi:10.1149/05819.0001ecst.

[27] Siracusano S, Baglio V, Di Blasi A, Briguglio N, Stassi A, Ornelas R, et al. Electrochemical characterization of single cell and short stack PEM electrolyzers based on a nanosized IrO2anode electrocatalyst. Int J Hydrogen Energy 2010;35:5558-68. doi:10.1016/j.ijhydene.2010.03.102. 
[28] Siracusano S, Di Blasi A, Baglio V, Brunaccini G, Briguglio N, Stassi A, et al. Optimization of components and assembling in a PEM electrolyzer stack. Int J Hydrogen Energy 2011;36:3333-9. doi:10.1016/j.ijhydene.2010.12.044.

[29] Nishiyama E, Murahashi T. Water transport characteristics in the gas diffusion media of proton exchange membrane fuel cell - Role of the microporous layer. J Power Sources 2011;196:1847-54. doi:10.1016/j.jpowsour.2010.09.055.

[30] Kitahara T, Konomi T, Nakajima H. Microporous layer coated gas diffusion layers for enhanced performance of polymer electrolyte fuel cells. J Power Sources 2010;195:2202-11. doi:10.1016/j.jpowsour.2009.10.089.

[31] Popov BN, Park S, Lee J. Effect of Gas Diffusion Layer Structure on the Performance of Polymer Electrolyte Membrane Fuel Cell. 2017.

doi:10.1002/9783527803873.ch17.

[32] Park J, Oh H, Lee Y Il, Min K, Lee E, Jyoung JY. Effect of the pore size variation in the substrate of the gas diffusion layer on water management and fuel cell performance. Appl Energy 2016;171:200-12. doi:10.1016/j.apenergy.2016.02.132.

[33] Lettenmeier P, Kolb S, Burggraf F, Gago AS, Friedrich KA. Towards developing a backing layer for proton exchange membrane electrolyzers. J Power Sources 2016;311:153-8. doi:10.1016/j.jpowsour.2016.01.100.

[34] Zielke L, Fallisch A, Paust N, Zengerle R, Thiele S. Tomography based screening of flow field / current collector combinations for PEM water electrolysis. RSC Adv 2014;4:58888-94. doi:10.1039/C4RA12402B.

[35] Mo J, Dehoff RR, Peter WH, Toops TJ, Green JB, Zhang F-Y. Additive manufacturing of liquid/gas diffusion layers for low-cost and high-efficiency hydrogen production. Int J Hydrogen Energy 2016;41:3128-35. doi:10.1016/J.IJHYDENE.2015.12.111.

[36] Mo J, Kang Z, Yang G, Retterer ST, Cullen DA, Toops TJ, et al. Thin liquid/gas diffusion layers for high-efficiency hydrogen production from water splitting. Appl Energy 2016;177:817-22. doi:10.1016/j.apenergy.2016.05.154.

[37] Mo J, Steen III SM, Retterer S, Cullen DA, Terekhov A, Zhang F-Y. Mask-Patterned Wet Etching of Thin Titanium Liquid/Gas Diffusion Layers for a PEMEC. ECS Trans 2015;66:3-10. doi:10.1149/06624.0003ecst.

[38] Kang Z, Mo J, Yang G, Retterer ST, Cullen DA, Toops TJ, et al. Investigation of thin/well-tunable liquid/gas diffusion layers exhibiting superior multifunctional performance in low-temperature electrolytic water splitting. Energy Environ Sci 2017;10:166-75. doi:10.1039/C6EE02368A.

[39] Majasan JO, Cho JIS, Dedigama I, Tsaoulidis D, Shearing P, Brett DJL. Two-phase flow behaviour and performance of polymer electrolyte membrane electrolysers: Electrochemical and optical characterisation. Int J Hydrogen Energy 2018. doi:10.1016/J.IJHYDENE.2018.07.003.

[40] Taiwo OO, Heenan TMM, Finegan DP, Brett DJL, Shearing PR, Paz-García JM, et al. Microstructural degradation of silicon electrodes during lithiation observed via operando X-ray tomographic imaging. J Power Sources 2017.

doi:10.1016/j.jpowsour.2016.12.070.

[41] Lu X, Taiwo OO, Bertei A, Li T, Li K, Brett DJL, et al. Multi-length scale tomography for the determination and optimization of the effective microstructural properties in novel hierarchical solid oxide fuel cell anodes. J Power Sources 2017. 
doi:10.1016/j.jpowsour.2017.09.017.

[42] Kulkarni N, Kok MDR, Jervis R, Iacoviello F, Meyer Q, Shearing PR, et al. The effect of non-uniform compression and flow-field arrangements on membrane electrode assemblies - X-ray computed tomography characterisation and effective parameter determination. J Power Sources 2019. doi:10.1016/j.jpowsour.2019.04.018.

[43] Feldkamp LA, Davis LC, Kress JW. Practical cone-beam algorithm. J Opt Soc Am A 1984. doi:10.1364/JOSAA.1.000612.

[44] Puncreobutr C, Lee PD, Hamilton RW, Phillion AB. Quantitative 3D characterization of solidification structure and defect evolution in Al alloys. JOM 2012. doi:10.1007/s11837-011-0217-9.

[45] Cooper SJ, Bertei A, Shearing PR, Kilner JA, Brandon NP. TauFactor: An opensource application for calculating tortuosity factors from tomographic data. SoftwareX 2016;5:203-10. doi:10.1016/j.softx.2016.09.002.

[46] Schalenbach M, Tjarks G, Carmo M, Lueke W, Mueller M, Stolten D. Acidic or Alkaline? Towards a New Perspective on the Efficiency of Water Electrolysis. J Electrochem Soc 2016. doi:10.1149/2.0271611jes.

[47] Xu J, Li Q, Christensen E, Wang X, Bjerrum NJ. Platinum activated IrO2/SnO2 nanocatalysts and their electrode structures for high performance proton exchange membrane water electrolysis. Int J Electrochem Sci 2013.

[48] Epstein N. On tortuosity and the tortuosity factor in flow and diffusion through porous media. Chem Eng Sci 1989. doi:10.1016/0009-2509(89)85053-5.

[49] Tjaden B, Cooper SJ, Brett DJ, Kramer D, Shearing PR. On the origin and application of the Bruggeman correlation for analysing transport phenomena in electrochemical systems. Curr Opin Chem Eng 2016.

doi:10.1016/j.coche.2016.02.006.

[50] Elsøe K, Grahl-Madsen L, Scherer GG, Hjelm J, Mogensen MB. Electrochemical Characterization of a PEMEC Using Impedance Spectroscopy. J Electrochem Soc 2017;164:F1419-26. doi:10.1149/2.0651713jes.

[51] J.O Majasan, J.I.S Cho, M. Maier, I. Dedigama P. S and DJ. B. Effect of Anode Flow Channel Depth on the Performance of Polymer Electrolyte Membrane Water Electrolyser. ECS Trans 2018;85:1593-603. doi:10.1149/08513.1593ecst.

[52] Dedigama I, Angeli P, Ayers K, Robinson JB, Shearing PR, Tsaoulidis D, et al. In situ diagnostic techniques for characterisation of polymer electrolyte membrane water electrolysers - Flow visualisation and electrochemical impedance spectroscopy. Int J Hydrogen Energy 2014;39:4468-82. doi:10.1016/j.ijhydene.2014.01.026.

[53] Yuan X-Z, Song C, Wang H, Zhang J. Electrochemical Impedance Spectroscopy in PEM Fuel Cells. Electrochem. Impedance Spectrosc. PEM Fuel Cells, 2010, p. 95138. doi:10.1007/978-1-84882-846-9.

[54] Van Der Merwe J, Uren K, Van Schoor G, Bessarabov D. Characterisation tools development for PEM electrolysers. Int. J. Hydrogen Energy, vol. 39, 2014, p. 1421221. doi:10.1016/j.ijhydene.2014.02.096.

[55] Pivac I, Barbir F. Inductive phenomena at low frequencies in impedance spectra of proton exchange membrane fuel cells - A review. J Power Sources 2016;326:112-9. doi:10.1016/J.JPOWSOUR.2016.06.119.

[56] Dedigama I, Angeli P, Van Dijk N, Millichamp J, Tsaoulidis D, Shearing PR, et al. 
Current density mapping and optical flow visualisation of a polymer electrolyte membrane water electrolyser. J Power Sources 2014;265:97-103. doi:10.1016/j.jpowsour.2014.04.120. 